DOE/NASA/20485-79/5

NASA TM-79248

\title{
EVALUATION OF CLEANERS FOR PHOTOVOLTAIC MODULES EXPOSED IN AN OUTDOOR ENVIRONMENT
}

W. D Knapp

National Aeronautics and Space Admınistration Lewis Research Center

October 1979

Prepared for

U.S. DEPARTMENT OF ENERGY

Energy Technology

Distributed Solar Technology Division 
NOTICE

This report was prepared to document work sponsored by the United States Government. Nelther the United States nor its agent, the Unlted States Department of Energy, nor any Federal employees, nor any of their contractors, subcontractors or thelr employees, makes any warranty, express or implied, or assumes any legal liability or responsibility for the accuracy, completeness, or usefulness of any information, apparatus, product or process disclosed, or represents that its use would not infringe privately owned rights. 
DOE/NASA/ 20485-79/5

NASA TM-79248

EVALUATION OF CLEANERS

FOR PHOTOVOLTAIC

MODULES EXPOSED IN AN

OUTDOOR ENVIRONMENT

W. D. Knapp

National Aeronautics and Space Administration

Lewis Research Center

Cleveland, Ohio 44135

October 1979

Work performed for

U. S. DEPARTMENT OF ENERGY

Energy Technology

Distributed Solar Technology Division

Washington, D. C. 20545

Under Interagency Agreement DE-A I01-79ET20485 


\section{SUMMARY}

Power recovery of silicone encapsulated and glass-covered photovoltaic modules, exposed for 2 years to a suburban environment, was measured after washing with a variety of cleaners including detergents, abrasive soap, and hydrocarbon solvents. Silicone encapsulated modules in operating environments may experience significant power losses or require extensive periodic cleaning. Glass front-faced modules in similar situations are much less affected. Organic hydrocarbon solvents or abrasives were found to be about five times more effective than mild detergents in cleaning silicone encapsulated modules.

\section{INTRODUCTION}

The NASA/Lewis Research Center is operating the National Photovoltaic Systems Test Facility (STF) for the Department of Energy at Cleveland, Ohio as part of the National Photovoltaic Energy Program (ref. 1, 2). A portion of the STF operations involves the evaluation of array performance under field environmental conditions. Terrestrial solar cell performance is dependent, in part, upon surface contamination which diminishes light transmission. Thus, it is important to evaluate the effect of accumulation arid removal of surface contamination on module performance.

The STF $10 \mathrm{KW}$ array (initial Block I Purchase) was cleaned after 1 year with mild commercial detergents but the results were judged unsatisfactory because adherent surface deposits were not completely removed. Subsequently, to determine whether a different cleaning procedure would be more effective, an evaluation of other cleaners was made. Modules were cleaned with nine different, readily available cleaners. The increase in module maximum power output due to cleaning was measured and the increase in performance versus cleaning time ( $\sim$ cost) was also considered. This paper presents the results of this evaluation.

The reader who intends to apply the information contained herein to an actual field situation should be appraised of the limitations of the investigation. It should be noted that the long-term compatibility between the various cleaners and the module encapsulant material was not evaluated and field operational safety procedures, required with some special cleaners, are not treated in this report.

\section{APPARATUS AND PROCEDURES}

\section{Modules}

The 19 modules used in this cleaning test were DOE Block 1 modules ( $46 \mathrm{KW}$ Purchase) which had been exposed since mid-1976. The manufacture types evaluated were 11 aluminum backed Sensor Technology 
modules having a silicone encapsulant and 8 aluminum backed Spectrolab modules with a glass front face and silicone sealant. The silicone encapsulated modules in this test were field cleaned with detergents in June 1977 before this special hand-cleaning in August 1978.

\section{Cleaners}

The cleaners used in this evaluation can be divided into four different types depending on their primary cleaning action.

(1) Hydrocarbon solvents

(2) Abrasive soap

(3) Mixture of hydrocarbon solvent and detergent

(4) Household and laboratory detergents

The hydrocarbon solvents used should dissolve the mineral hydrocarbons which are not removed by detergents. The abrasive soap should mechanically remove most deposits on the surface. The mixed cleaner should remove both mineral and nonmineral deposits. The household detergents should be most effective in removing animal and vegetable fats and any loose dirt.

The cleaners evaluated and their type of cleaning action are presented in Table 1.

\section{Test Site}

The test location was the National Photovoltaic Systems Test Facility at the Lewis Research Center, Cleveland, Ohio, a suburban area which is primarily residential with a shopping center 3 miles to the west (upwind). To the east (downwind) are research facilitiles and light industry with one heavy industrial plant 2 miles distant and Cleveland Hopkins International Airport 1 mile away. Commuter auto traffic going to and from metropolitan Cleveland, which is over 10 miles downwind, also passes the area.

\section{Experimental Procedure}

During the field cleaning of the STF solar array in August 1978, several panels of modules were not field cleaned but were removed from the field for inspection, evaluation, and hand-cleaning. The steps in the procedure used for silicone encapsulated Sensor Technology panels follow. 
Physical Inspection. - The modules were visually inspected for surface contamination under a microscope to determine the nature of the deposits. A photomicrograph was made of the surface contamination.

Current-Voltage Curves. - The current-voltage characteristics of the modules were determined using the LeRC large area pulsed solar simulator at $28^{\circ} \mathrm{C}$ and $A M 1$ intensity. The maximum power $\left(P_{\max }\right.$ ) was determined from the $1-V$ curve and compared to the maximum power of "as received" unexposed modules to calculate the change in performance. The instrument accuracy of the measurement of $P_{\max }$ is \pm 2.5 percent excluding standard cell errors and technique variations. Only normal incidence $1-V$ curves were obtained.

Cleaning. - The module surfaces were hand-cleaned at ambient temperature $\left(26^{\circ} \mathrm{C}\right)$ with a sponge or rag, rinsed with solvent or water, and dried with a clean rag during a time period. Vigorous hand-rubbing was applied with a sponge or rag during sequential timed periods of $60,60,180$ and 300 seconds. Nine different cleaners were used and each module was cleaned with only a single cleaner throughout all the tests. The solvents and tap water were kept in and applied from 1gallon bottles.

The residence time of hydrocarbon solvents on silicone encapsulated modules was kept to a minimum to prevent the solvent from penetrating the silicone. Some solvents will cause swelling in both Sylgard and RTV silicone rubber when they are immersed for 7 days at ambient temperatures according to references 3 and 5 . The washing and rinsing of the modules in this test produced no noticeable swelling.

Post-Cleaning Current-Vol tage Curves. - Effectiveness of the various cleaners in removing surface contamination was determined by comparing maximum power $\left(P_{\max }\right)$ before and after each timed cleaning period.

Encapsulant Degradation. - In an effort to determine encapsulant degradation, silicone rubber was carefully removed from selected modules, placed over a solar cell in the solar simulator, and the subsequent change in cell short circuit current determined. Conditions included: (1) never exposed, (2) dirty, after 2 years field exposure, (3) after $120 \mathrm{~min} / \mathrm{M}^{2}$ solvent cleaning, and (4) after $5,000 \mathrm{~min} / \mathrm{M}^{2} \mathrm{sol}$ vent (acetone) cleaning.

Comparison of Glass to Silicone Surfaces. - In order to compare glass to silicone surfaces for degradation and cleaning rate, eight of the Spectrolab modules (glass-covered) from the STF were inspected and cleaned. These modules had not been washed for the 2 years they were on exposure. Two each of these modules were cleaned with Alconox, acetone, Lava soap and Joy. They were scrubbed for two 2-minute periods and rinsed with tap water. 
Analytical Methods for Surface Contamination. - Different modules than those used in cleaning, but from the same field sample, were used to obtain an organic chemical analysis of the surface contamination using infrared spectroscopy. The modules were first rinsed with carbon tetrachloride and the resulting solution was evaporated on a steam bath to remove the carbon tetrachloride. The concentrated samples of contaminants were then filtered to remove particulates and analyzed using an infrared spectrophotometer. Basel ine spectra were obtained on samples from the surface and the interior of the silicone encapsulant material using "as received" modules that were never exposed to the outdoors. Spectra were also obtained from Solar Power Corporation modules in addition to the two previously discussed.

\section{RESULTS AND DISCUSSION}

\section{Physical Inspection}

Visual observations and inspection of the Sensor Technology module surface indicated black, gray and white tenacious deposits on the modules. The black deposits were up to $1 \mathrm{MM}$ in size. The majority of the spots, however, were less than $0.05 \mathrm{MM}$ in size. None of the deposits appeared to be granular and they could not be brushed off. Ordinary loose dust and bird deposits were removed for the most part by rain and melting snow. The nature of the dirt is shown in the scaled photomicrograph presented in Figure 1 .

Inspection of the glass surface of the Spectrolab modules revealed only light dust and very few black spots. No detailed study was made of deposit composition.

\section{Cleaner Evaluation}

The cleaning effectiveness and rate were evaluated using the $P_{\max }$ values taken from $I-V$ curves recorded before and after each timed period during the cleaning process. Based on the rate of dirt removal from a silicone surface, as determined in this study, the cleaners fell into two groups. The best performance cleaners (Group I) were the hydrocarbon solvents and the abrasive soap. Group II contained the detergents and mixed solvent-detergent. The Group I cleaners were about twice as effective as Group II cleaners.

Data for Group I cleaners are shown in Figure 2. The solvents have a faster initial dirt removal rate than the abrasive soap but all of these cleaners produced at least an 18 percent increase in $P_{\max }$ after scrubbing for over $60 \mathrm{~min} / \mathrm{M}^{2}$. Little additional increase in $P_{\max }$ was noted at longer scrub times. The solvent cleaners are technique-sensitive because of their generally high vapor pressure. The solvent may evaporate and produce a residue if the module is not sufficiently rinsed. 
Data for Group $\|$ cleaners are shown in Figure 3. This group produced only 6 to 13 percent increase in $P_{\max }$ after $60 \mathrm{~min} / \mathrm{M}^{2}$. It should be noted that Lestoil, the cleaner containing a small amount of petroleum distillates, was better than the detergents. The detergent-acetone mixture performed about the average of the two individual cleaners.

A visual comparison of three silicone encapsulated modules is shown in Figure 4. Effectiveness of the various cleaners is apparent.

\section{Comparison of Glass.to Silicone Surfaces}

The mean $P_{\max }$ of the exposed and cleaned silicone encapsulated modules and glass-covered modules compared to the mean $P_{\max }$ of their respective "as received" unexposed modules are shown in Figure 5. The silicone encapsulated modules were those cleaned with Group 1 cleaners and shown in Figure 2.

The average of the eight glass-covered modules (two groups of four removed in summer and winter) had degraded in $\mathrm{P}_{\max }$ only about 11 percent in power as compared to about 31 percent for the silicone encapsulated modules. The performance recovery was rapid during the initial cleaning but never achieved the original power level. No difference was noted in the effectiveness of the various cleaners on the glass-covered modules. The unrecovered power was about 8 percent for glass-covered and 9 percent for silicone encapsulated modules. By examining the short circuit current for the glass-covered modules, it was concluded that about half of the unrecovered power was due to residual dirt or darkening of the encapsulant. The other half may be due to changes in cell fill factor. One possible cause for altered fill factor was observed by JPL (ref. 5) and was believed to be caused by the interaction of moisture with the cell contacts. However, this type of degradation was not observed after 1 year exposure of other glass modules (ref. 6).

Recognizing that the cleaning time is related to cost, one can see from Figure 5 that extending the cleaning time may not be cost effective due to the small benefit obtained after $20 \mathrm{~min} / \mathrm{M}^{2}$. Also, the cleaning time advantage of a glass surface compared to the silicone surface is readily apparent.

In order to determine if there were any performance loss in neverexposed modules, 18 glass-covered modules and a single silicone encapsulated module that had been kept in indoor storage over the same 2-year period were measured. The average $P_{\max }$ compared to the respective "as received" modules was found to be within 1.5 percent for the glasscovered modules and 2.7 percent for the silicone encapsulated module. These values are near experimental measurement error and are shown in Figure 5 . 


\section{Surface Contamination}

Infrared spectra of the baseline "as received" never-exposed module surface and interior indicate the presence of organic groups. The three field-exposed module types revealed three different hydrocarbon spectra. None of these spectra matched the never-exposed baseline spectrum nor were they similar to each other. The spectra are multi-component and probably result from combinations of the type and history of the individual vendor's silicone potting material and the various organic environmental pollutants at the exposure site.

\section{Silicone Condition}

The results from the measurement of light transmission through the silicone rubber, as measured by a solar cell, are given below.

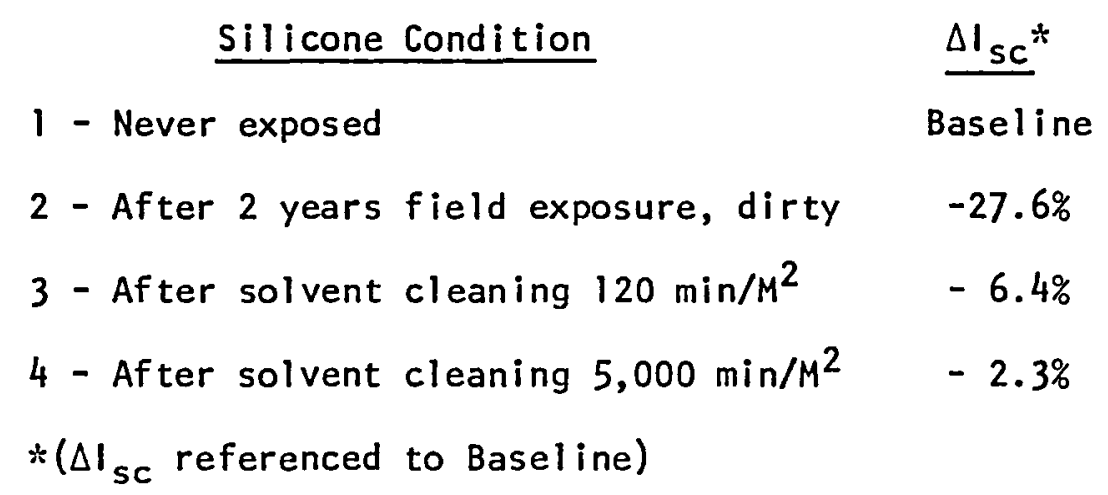

The change in $I_{s c}$ can be correlated with the power loss for equivalent conditions. For example, the power loss for conditions 2 and 3 were 30 percent and 9 percent, respectively. Although power loss was not measured for condition 4, one might expect that after extensive cleaning the module power would be near the "as received" module output power. The small difference ( $\sim 2$ percent) between the current and power loss may be due to differences in the $1-V$ characteristics of the "as received" modules and the measured modules.

\section{Labor Time Considerations}

Laboratory Cleaning Methods. - The percentage increase in power as a function of laboratory hand-labor time for the detergent, abrasive and solvent-type cleaners is shown for silicone encapsulated modules in Figure 6 . The solvent-type cleaners are less labor intensive because of their rapid cleaning action. They also produce almost an order of magnitude more power recovery than detergents. Nevertheless, the solvent types 
are more costly, involve handling, atmospheric pollution, health exposure, and safety problems not found with detergent-type cleaners.

With the hand-cleaning technique, one module was washed at a time. For comparison purposes, the reader can consider each module to be about 5 watts in peak power and about one-tenth of a square meter in area.

Field Cleaning Methods. - Various cleaning methods that might be utilized for module cleaning in the field are listed below.

(1) Laboratory bench techniques

(2) Window-washing techniques

(3) Remote operated mechanized equipment

The first method of laboratory bench hand-washing and scrubbing was the method utilized in this study. Window-washing type techniques have been used for the cleaning of the $10 \mathrm{KW}$ STF solar array. Mechanized methods for array cleaning, which would probably be the most efficient, have yet to be developed.

The entire $10 \mathrm{KW}$ Systems Test Facility array field has been washed twice since system startup using the window-washing techniques. Two different cleaners were used during the first field washing in June 1977. One-half the field was washed with Alconox and Tide and the other with Joy. This first washing was somewhat exploratory and utilized a long handle squeegee and chamois cloth drying operation. The second washing, in 1978, utilized only the detergent Joy and can be compared to the handcleaning. In both instances the field washing was done at night and rinsing was accomplished with a garden hose.

Laboratory versus Window-Washing Techniques. - Laboratory handcleaning of single modules would be expensive if applied to washing large numbers of silicone encapsulated modules in the field. An approximate labor relationship between the hand-washing technique and the fieldwashing techniques for detergents only is shown in Figure 7, for comparison purposes.

If we compare the July 1978 field-washing data with the hand-washing data, it can be seen that the field-washing technique results in comparable increases in power for one-tenth the labor. It should be recognized, however, that the field-cleaning technique using detergent removes only about 20 percent of the total environmental contamination present on the encapsulant. The use of solvent-type cleaners should remove almost all of the contaminants but application of such cleaners to a field operation is fraught with several problems, as indicated in the previous section. 
Examination and cleaning of the DOE Block $I$ silicone and glasscovered photovoltaic modules acquired in 1976 have indicated that:

(1) Silicone encapsulated modules in operating environments may experience significant power losses or require extensive periodic cleaning. Glass-covered modules in similar situations are much less affected. The power loss after 2 years exposure to a suburban environment and after cleaning was as follows:

After Exposure After Cleaning

$\begin{array}{lll}\text { Silicone encapsulated } & -31 \% & -9 \% \\ \text { Glass-covered } & -11 \% & -8 \%\end{array}$

(2) Organic hydrocarbon solvents or abrasives are about five times more effective than mild detergents in cleaning silicone encapsulated modules.

(3) A portion of power loss experienced in outdoor exposure is apparently not regained and is probably a result of factors other than surface contamination. 


\section{REFERENCES}

1. Forestieri, A.F., et al.: ERDA/Lewis Research Center Photovoltaic Systems Test Facllity. ERDA/NASA-1022/77/12, NASA TMX-73641, 1977.

2. Forestieri, A.F.: The ERDA/LeRC Photovoltaic Systems Test Facility. ERDA/NASA/1022-77/19, NASA TM-73787, 1977.

3. Fluid Resistance of Silastic Silicone Rubber. Bulletin 17 052A, Dow Corning, Mar. 1976.

4. Chemical Resistance of RTV Silicone Rubber. Bulletin No. TSR 1708, General Electric Co.

5. Griffith, J.S.; and Sollock, S.G.: Summary of Block I (46 KW) Module Testing. JPL-5101-27, Jet Propulsion Lab., May 2, 1977 .

6. Anagnostou, E.; and Forestieri, A.F.: Endurance Testing of First Generation (Block 1) Comercial Solar Cell Modules. DOE/NASA/1022-78/33, NASA TM-78922, 1978. 


\section{ACKNOWLEDGEMENTS}

1. H. Curtis, Photovoltaic Research Section, for providing normalized IV curves.

2. D. Kuivinen, Chemical Services Laboratory, for providing organic chemical analysis. 
table 1. - cleaners and cleaning action

\begin{tabular}{|c|c|}
\hline Cleaner & Cleaning Action \\
\hline \multicolumn{2}{|l|}{ Hydrocarbon solvents } \\
\hline Trichloroethane & Degreaser \\
\hline Toluene & Hydrocarbon solvent \\
\hline Acetone & $\begin{array}{l}\text { Miscible with water and nonpolar hydro- } \\
\text { carbons }\end{array}$ \\
\hline Engine Shampoo - Tap water rinse & Commercial auto engine degreaser \\
\hline \multicolumn{2}{|l|}{ Abrasive bar soap } \\
\hline Lava - Tap water & Abrasive \\
\hline \multicolumn{2}{|l|}{$\frac{\text { Mixiure of hydrocarbon solvent and }}{\text { detergent water }}$} \\
\hline $\begin{array}{l}50 \% \text { acetone and } 50 \% \text { (Joy in tap vater) } \\
\% \text { by volume mixture }\end{array}$ & $\begin{array}{l}\text { Miscible with water and nonpolar hydro- } \\
\text { carbons and detergent action }\end{array}$ \\
\hline \multicolumn{2}{|l|}{ Detergents } \\
\hline Joy - Tap water & $\begin{array}{l}\text { Mild domestic detergent (used as baseline } \\
\text { reference for comparison with the field } \\
\text { washing techniques) }\end{array}$ \\
\hline Lestoil - Tap water & $\begin{array}{l}\text { Household detergent (which contains small } \\
\text { amounts of hydrocarbon solvents) }\end{array}$ \\
\hline Alconox - Tap water & Laboratory detergent \\
\hline
\end{tabular}

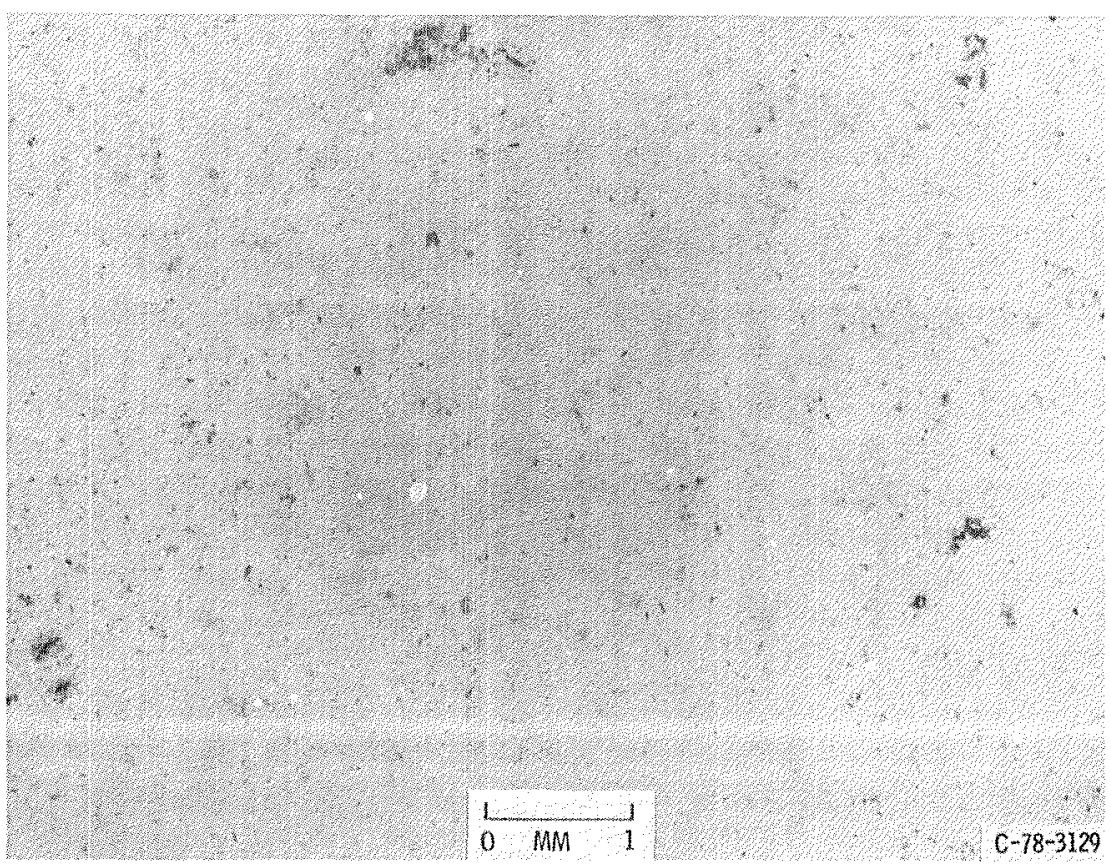

Figure 1." Photomicrograph of exposed silicone surfaced module. 


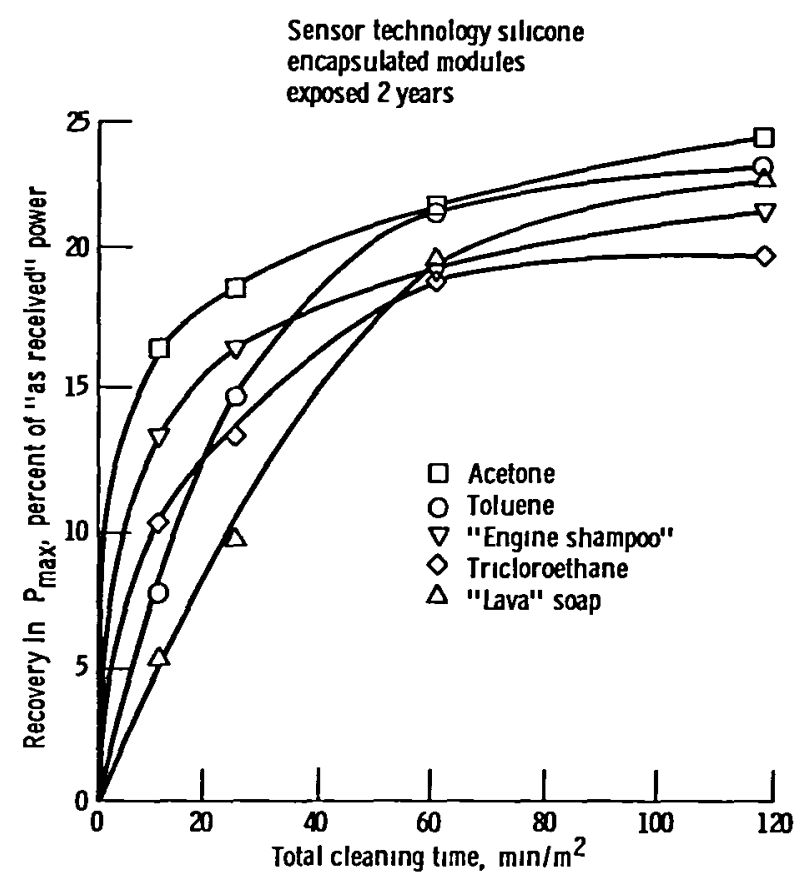

Figure 2 - Recovery in $P_{\max }$ as a function of specific cleaning tıme for group II cleaners

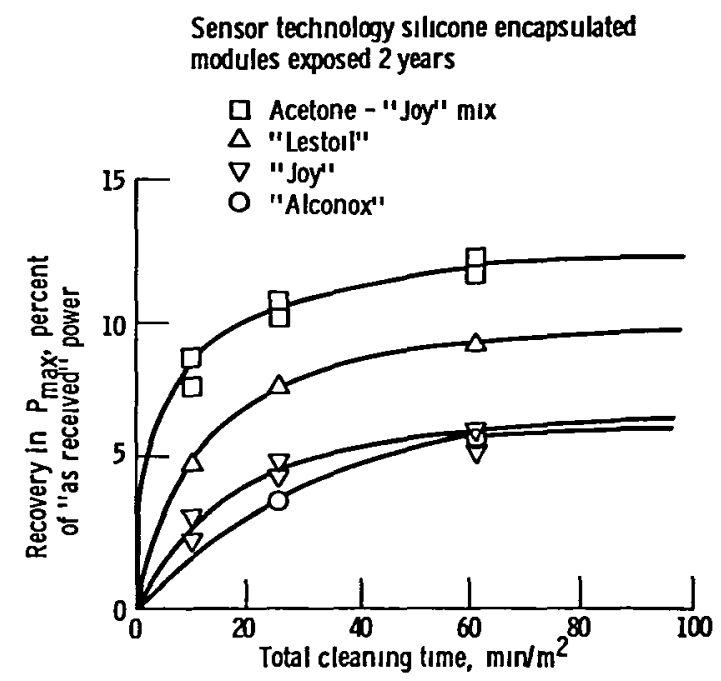

Figure 3 - Recovery in $P_{\max }$ as a function of specific cleanıng tıme for group II cleaners. 

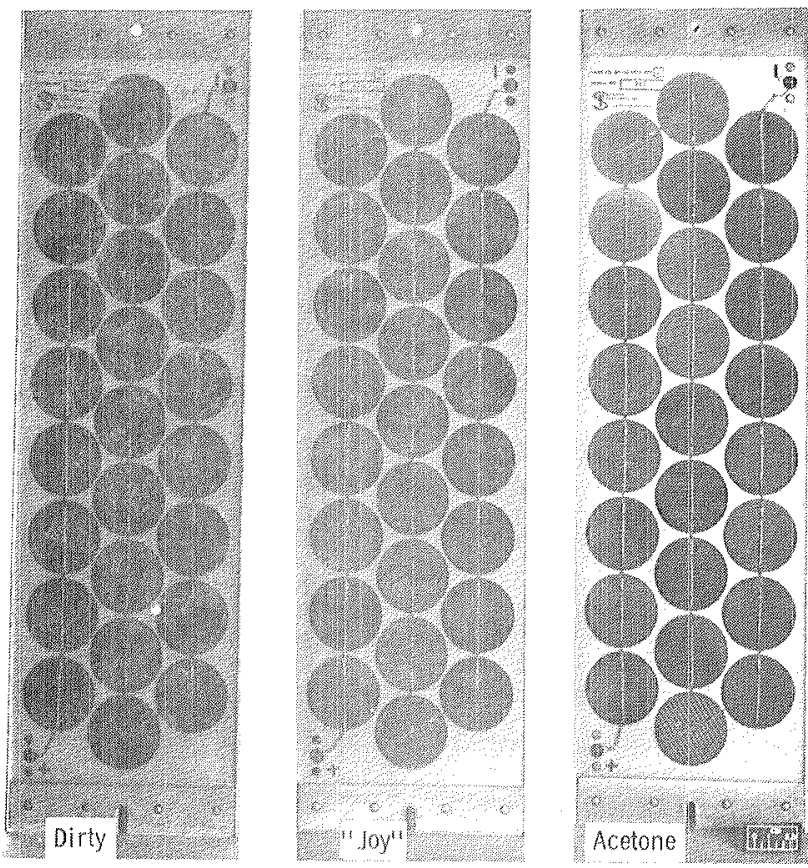

Figure 4. - Silicone encapsulated modules before and after cleaning.

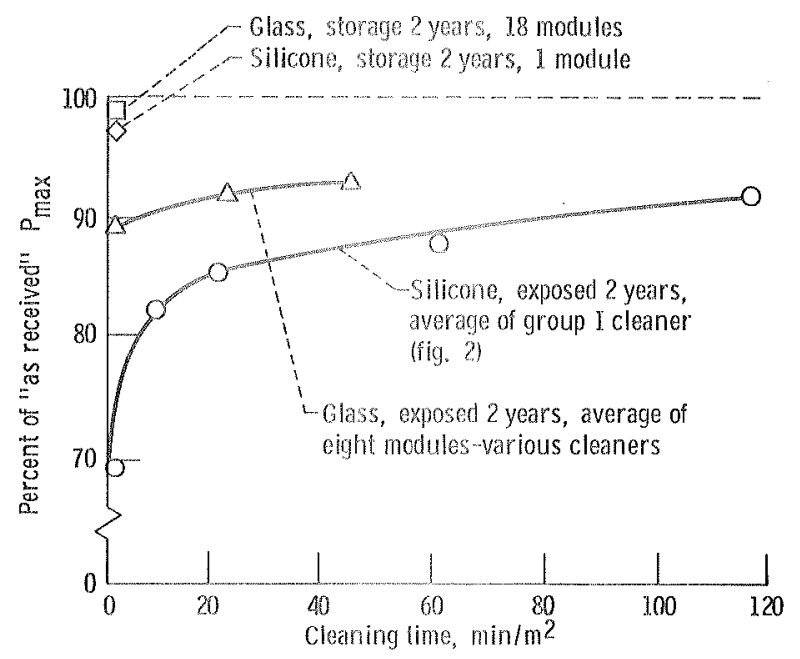

Figure 5. - Performance recovery as a function of cleaning time for silicone and glass encapsulated modules. 


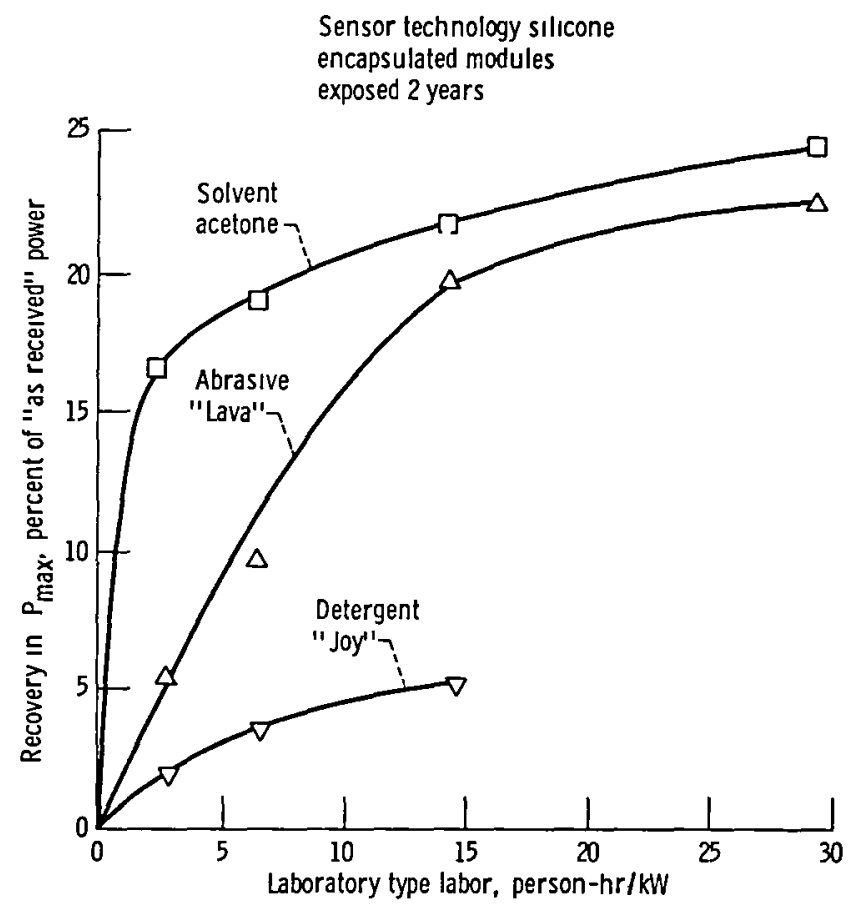

Figure 6 - Comparative laboratory type labor for different cleaners

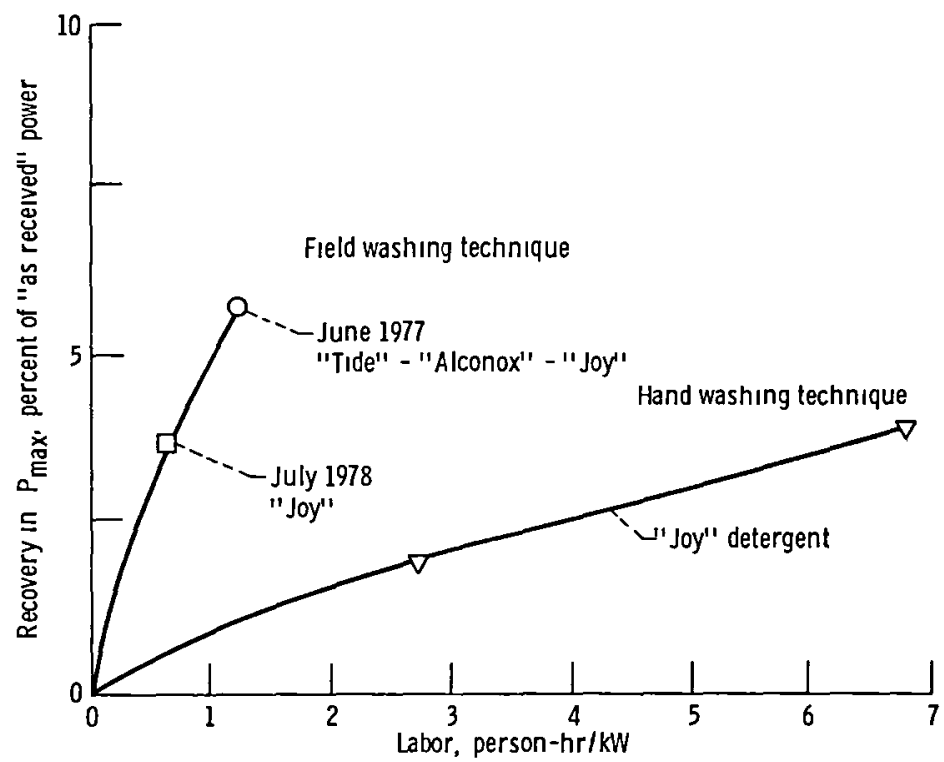

Figure 7 - Comparison of laboratory type hand washing and field washing technıques using detergent cleaners 


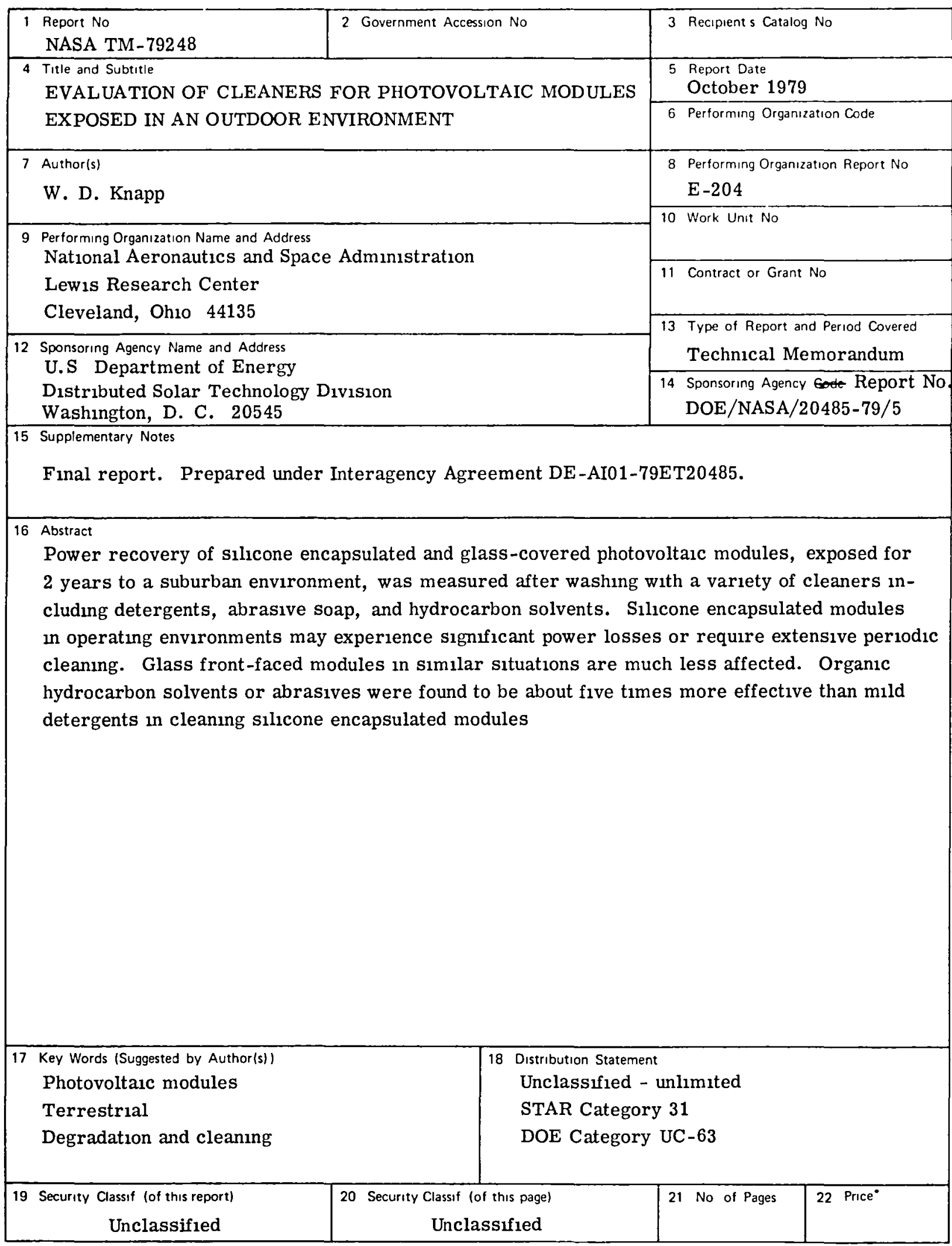

* For sale by the Natıonal Technical Informatıon Service, Sprıngfıeld, Virgınıa 22161 


\section{End of Document}

